\title{
Farmers' knowledge level of the extension recommendations to produce sugarcane in Luxor governorate, Egypt
}

\author{
Basheer A. A.*, Aboelenein M. A., Abdel Hafez M. M. I., Abdelsalam M. F. S. E. \\ Agricultural Extension and Rural Sociology Department, Faculty of Agriculture, Al-Azhar University, Assiut, Egypt
}

\begin{abstract}
The main objective of this research is to assess farmers knowledge level of extension recommendations to produce sugarcane in Luxor governorate. To achieve this objective, it aimed to: (a) Identify knowledge level of sugarcane growers in research zone, (b) Examine the relationship between level of knowledge level for respondents and their characteristics. To achieve the above objectives, a survey was carried out on 306 respondents in three villages in Luxor governorate; a questionnaire form was prepared and distributed among all respondents. The researchers followed up the process of data collection and were able to obtain responses from respondents in the governorate. Percentages, frequency distribution used for data processing and analyses using SPSS program. The results of field research indicated that the respondents had high knowledge level of two process Choose the right soil, And the date and method of planting (77.1\% and 57.2\%), respectively, While the results showed that the surveyed farmers had an average level of knowledge of the processes of hoeing the cane crop, preparing the land for cultivation, breaking, and supplying the cane crop, and selecting suitable seeds in proportions (83.7\%, 83.4\%, 73.5\%, 51.6\%). Arrangement, While the surveyed farmers had a low level of knowledge of patching the cane crop, fertilizing the cane crop, and irrigating the cane crop with rates $(94.1 \%, 76.5 \%$ and $60.5 \%)$, respectively.
\end{abstract}

Keywords: farmers' knowledge, sugarcane, extension recommendations, Luxor.

* Corresponding author: Basheer A. A.,

E-mail address: abdo6693@gmail.com 


\title{
مستوى معرفة الزراع بالتوصيات الإرشادية لإنتاج قصب السكر بمحافظة الأقصر بجمهورية مصر الإندية لإنية
}

\author{
عبد الناصر أحمد بشير عبيد ، مصطفى عبدالحميد ابو العنين ، محمد محمد إسماعيل عبدالحافظ ، محمود فوزى سالمان عبد السلام النجار \\ قسم الاقتصاد الزراعي ، كلية الزراعة ، جامعة الأزهر (فرع أسيوط) ، أسيوط ، جمهورية مصر العربية
}

استهدف هذا البحث بصفة رئيسية تحديد مستوى معرفة الزراع المبحوثين بالتوصيات الإرشادية لإنتاج محصول قصب السكر بمحافظة

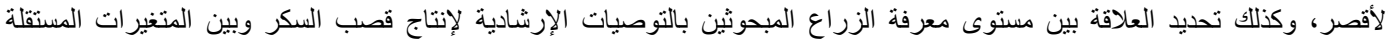

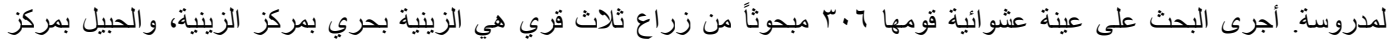

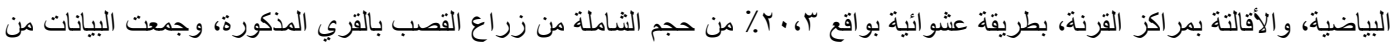

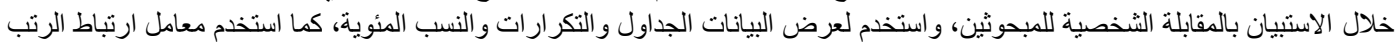

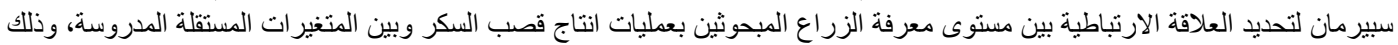

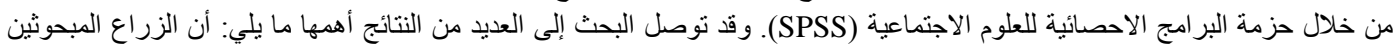

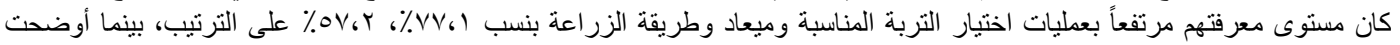

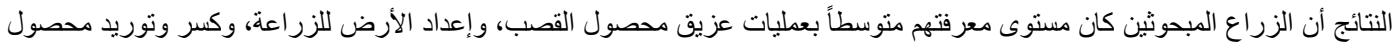

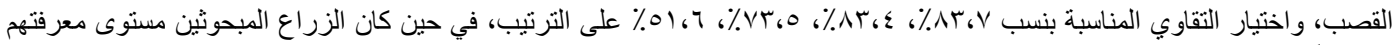

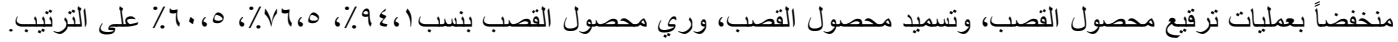

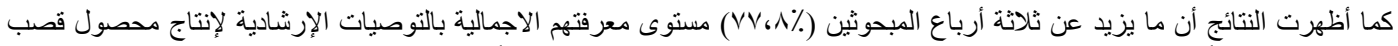

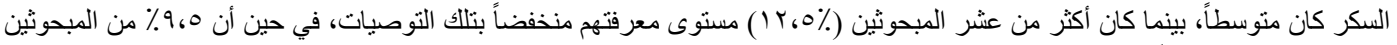

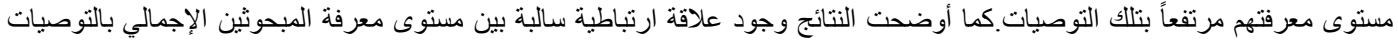

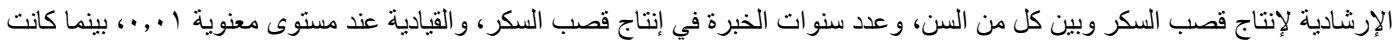

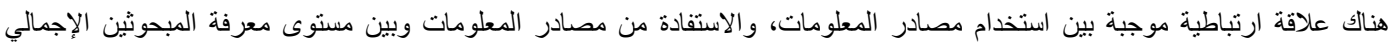

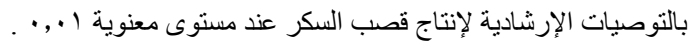




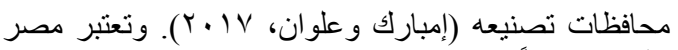

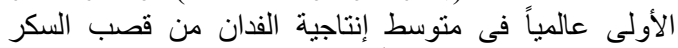

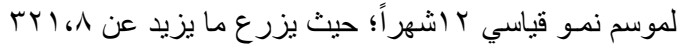

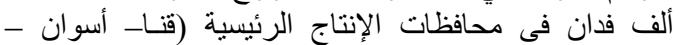

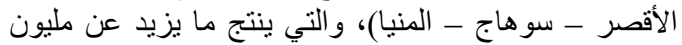

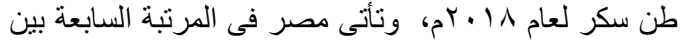

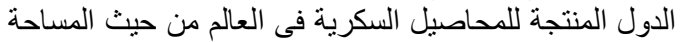

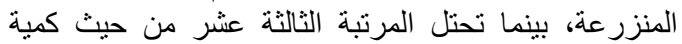
الإنتاج، مما بستلزم الحفاظ على هذا المحصول دئل من الإصـابات

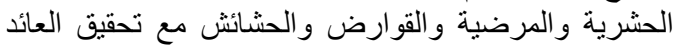

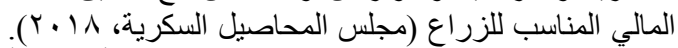

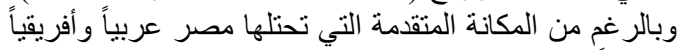

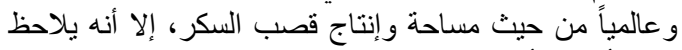

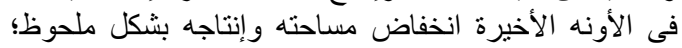

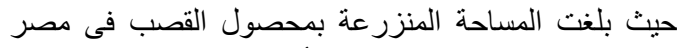

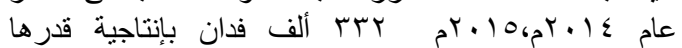

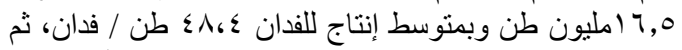

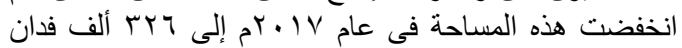

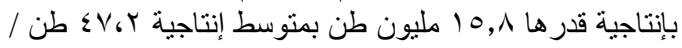

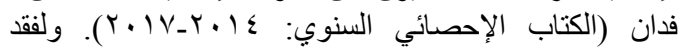

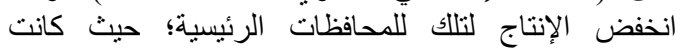

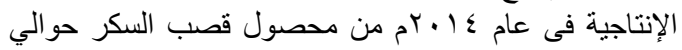

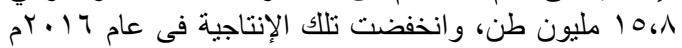
الى 10،10، مليون طن، واستمرت الإنتاجية فى الانىف الخفاض

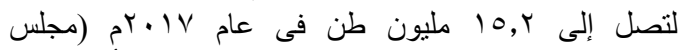

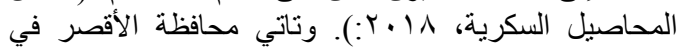

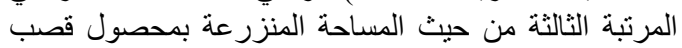

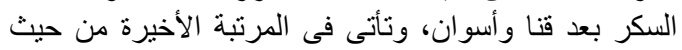
الإنتاجية بين محافظات الإنتاج الرئيسية، وتبلغ والنية الإنية المساحة

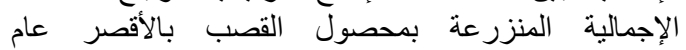

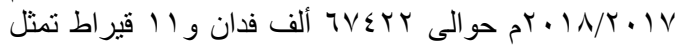

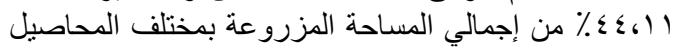

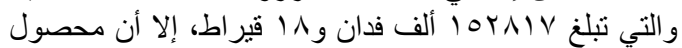

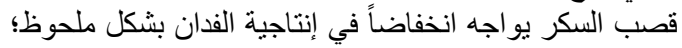

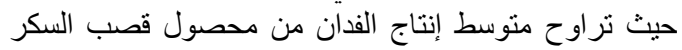

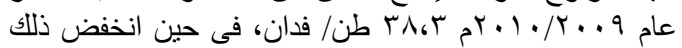

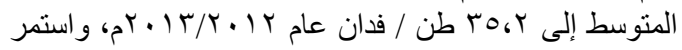

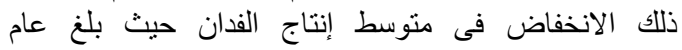

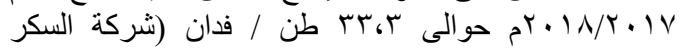

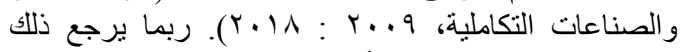

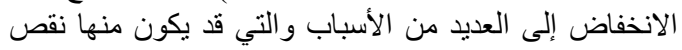

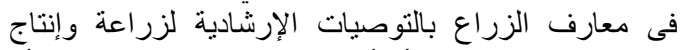

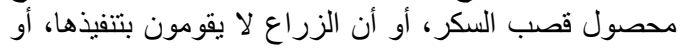

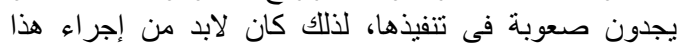

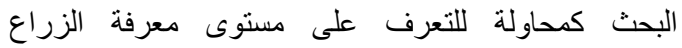

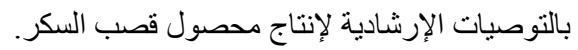

\section{مقدمة و مشكلة البحث}

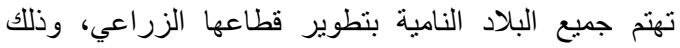

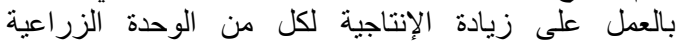

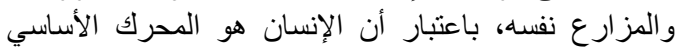

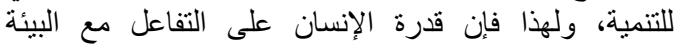

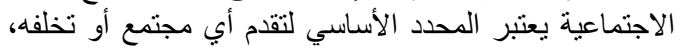

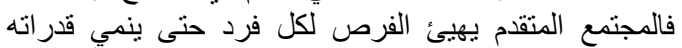

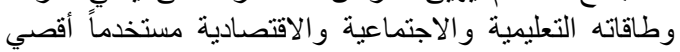

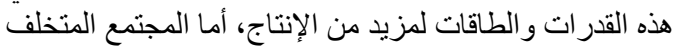

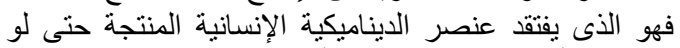

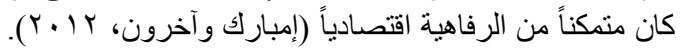

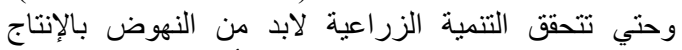

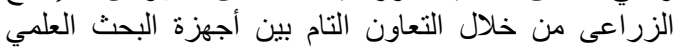

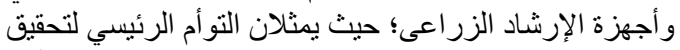

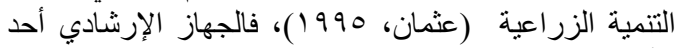

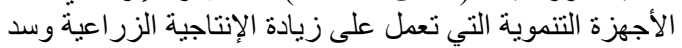

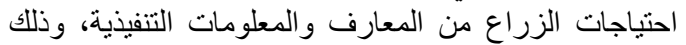

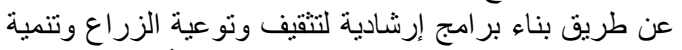

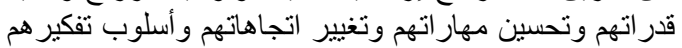

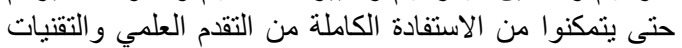

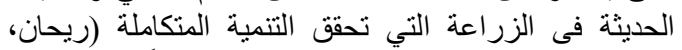

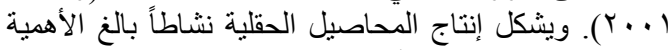

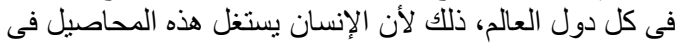

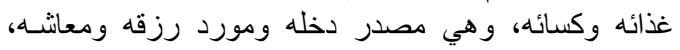

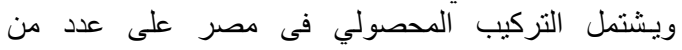

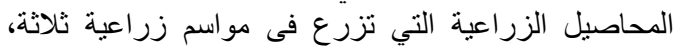

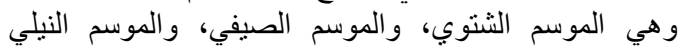

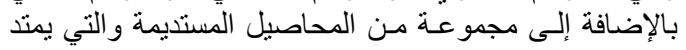

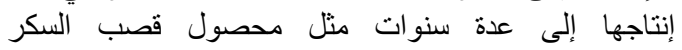

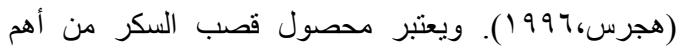

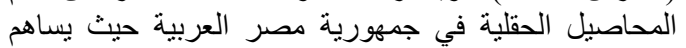

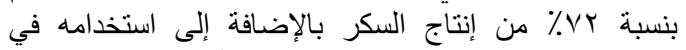

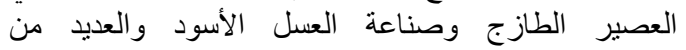

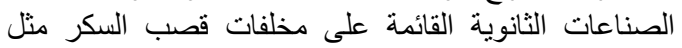

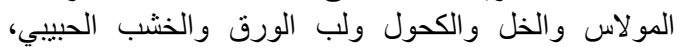

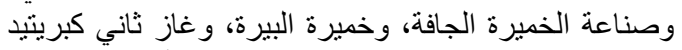

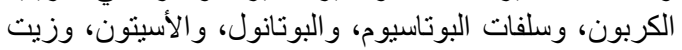

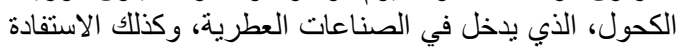

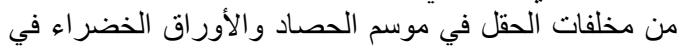

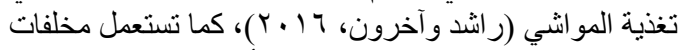

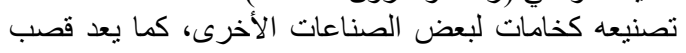

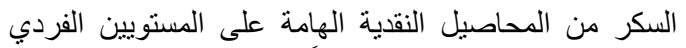

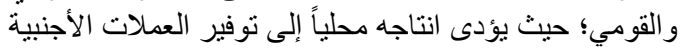

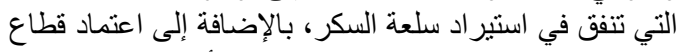

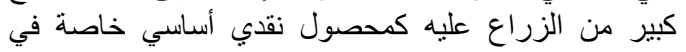


r- مساحة الحيازة الزراعية: تم قياسها بإجمالي مساحة

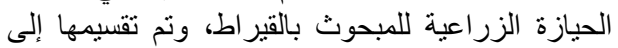

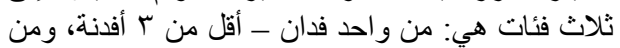

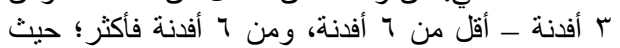

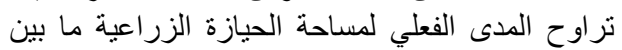

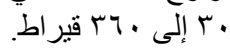

ع - المساحة المنزرعة بقصب السكر: تم قياسها بإجمالي

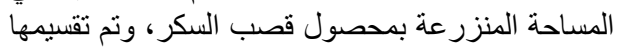

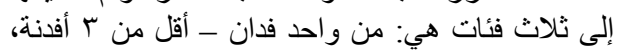

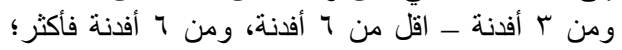
حيث تراوح المدى الفعلي لمساحة الحيازة الزراعية الفية ماكئ

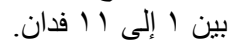
عدد سنوات الخبرة في إنتاج قصب السكر: نم قياسها

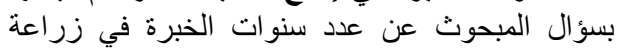

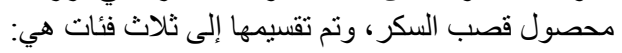

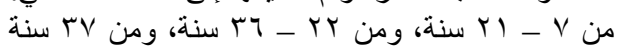

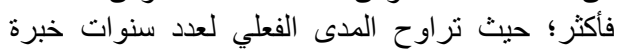
الزراع المبحوثين في زر اعة قصب السكر ما بين > إلى لئى • 0 سنة.

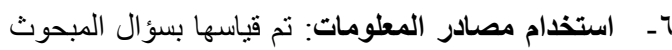

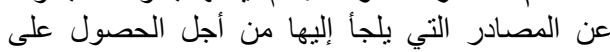

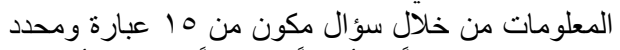

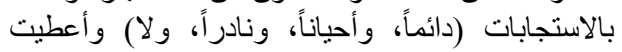

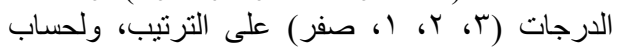

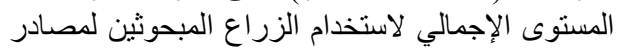

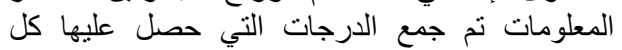

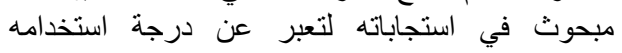

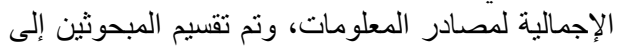

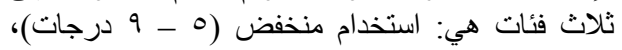

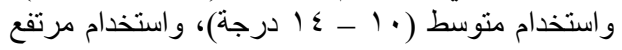

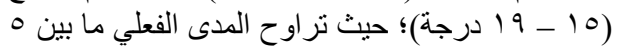

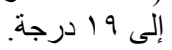

الاستفادة من مصادر المعلومات: تم قياسها بسؤال

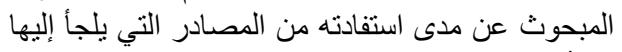

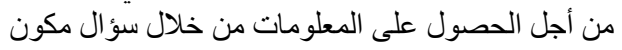

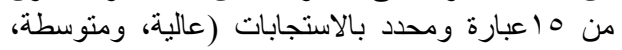

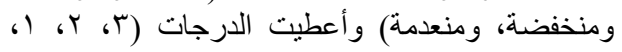

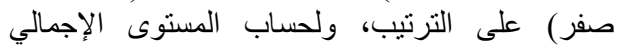

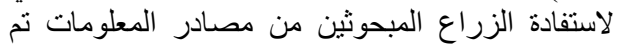

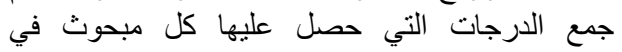

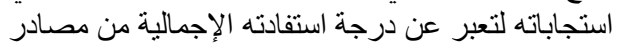

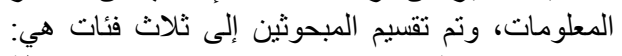

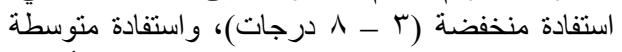

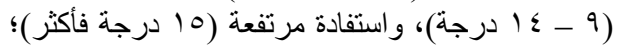
حيث تراوح الددى الفعلي ما بين بـ إلى (ولى 19 درجة.
أهداف البحث

من العرض السابق لمشكلة البحث يمكن تحديد أهداف البحث

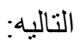

تحديد مستوى معرفة الزراع المبحوثين بالتوصيات الإرشادية لإنتاج محصول قصب الزب السكر بمنطقة البحث.

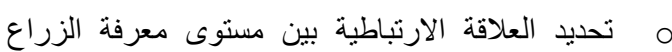

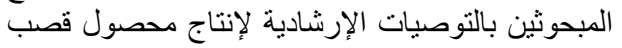
السكر وبين المتغيرات المستقلة المدروسة الإنتاج التالية: السن،

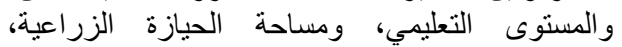

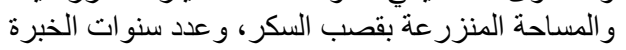

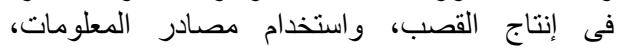

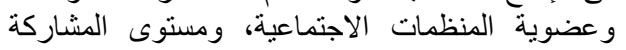
المجتمعية غير الرسمية، ودرجة القئماعية القية.

\section{الفروض البحثية}

لتحقيق هدف البحث تم صياغة الفرض البحثي التالي: توجد

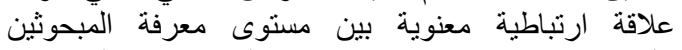

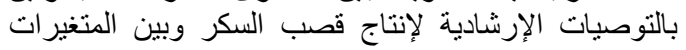

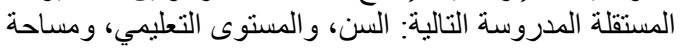

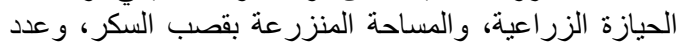

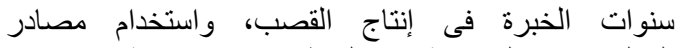

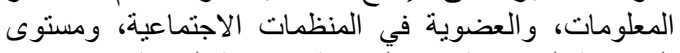

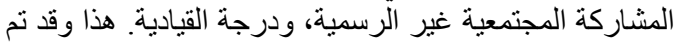
وضع الفرض الإحصائي المقابل في صورته الرئه الصفرية لاختية لاختبار صحة الفرض البحثي.

\section{طريقة إجراء البحث}

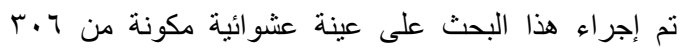

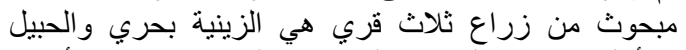

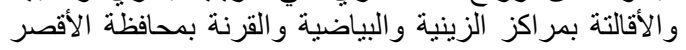

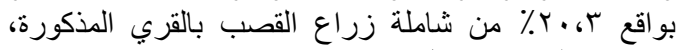

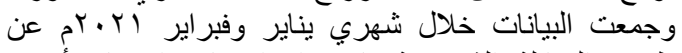
طريق المقابلة الثخصية باستخدام استمارة استبيان أعدات خصيصًا لهذا الغرض، واحتوت النقات على ما يلي:

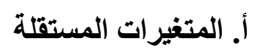

1 - السن: تم قياسه بعدد سنوات عمر المبحوث لأقرب سنة ميلادية وقت جمع البيانات.

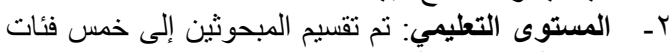

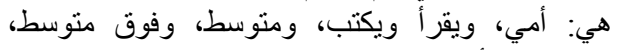

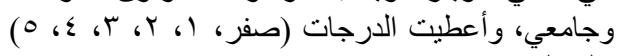
على الترتيب. 


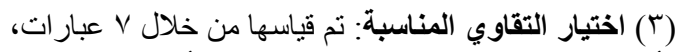

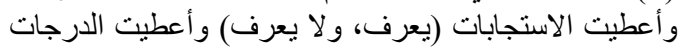

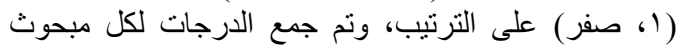

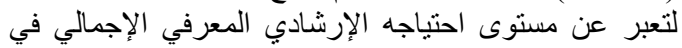

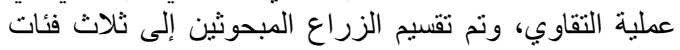

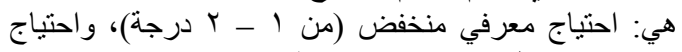

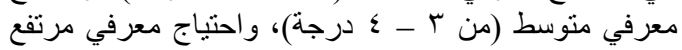

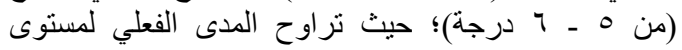
الاحتياج الإرشادي المعرفي ما بين إن إلى 1 درجة.

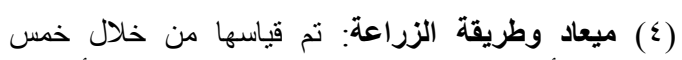

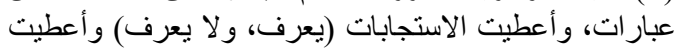

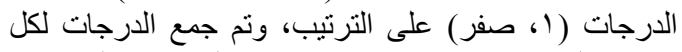

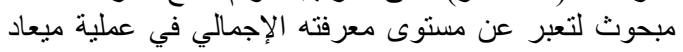

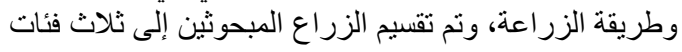

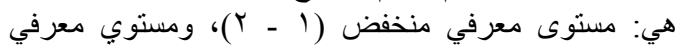

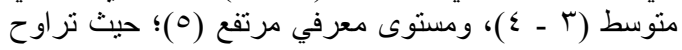

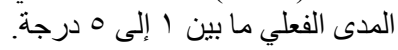

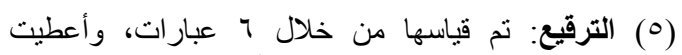

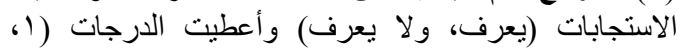

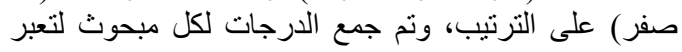

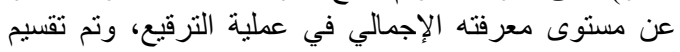

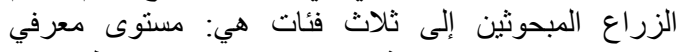

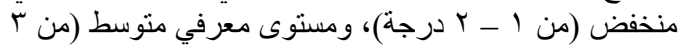

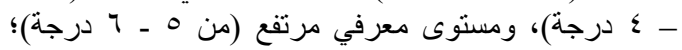

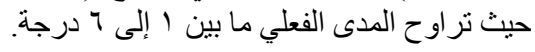

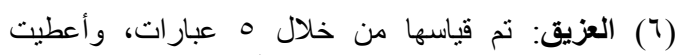

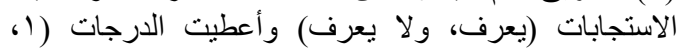

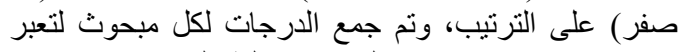

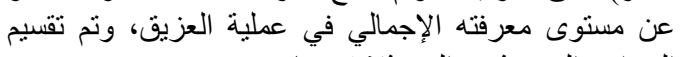

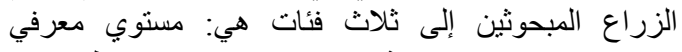

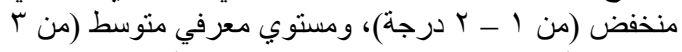

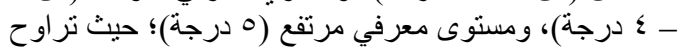

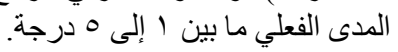

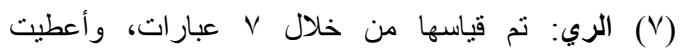

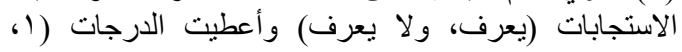

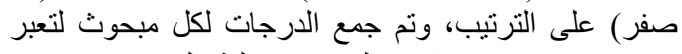

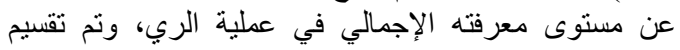

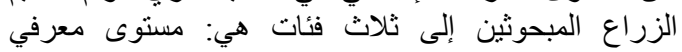

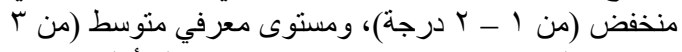

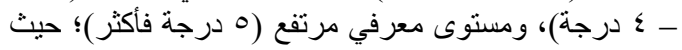
تراوح المدى الفعلي ما بين ا إلى ل د درجة.

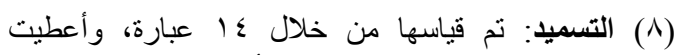

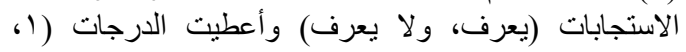
صفر) على الترنيب، وتم جمع الدرجات لكاب لكل مبحوث لتعبر الترات
العضوية في المنظمات الاجتماعية: نم قياسها بسؤال

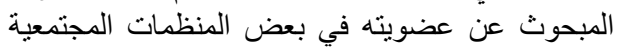

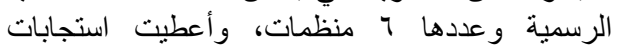

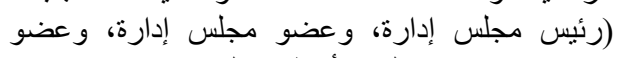

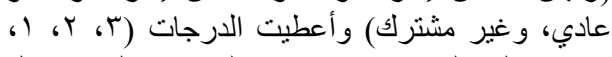

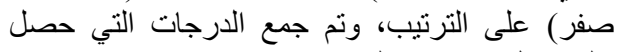

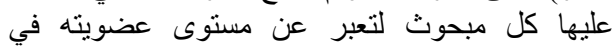

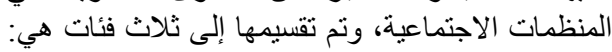

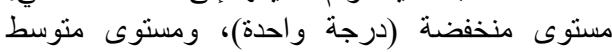

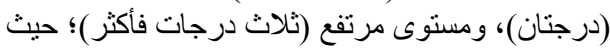

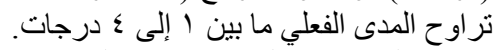

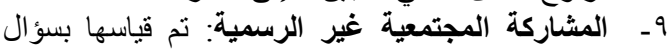

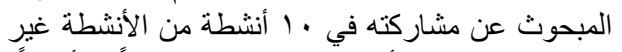

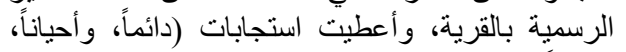

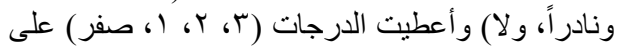

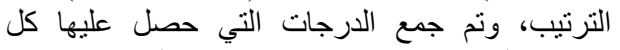

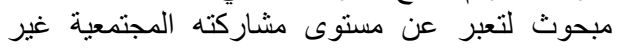

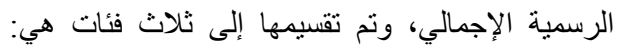

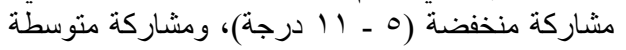

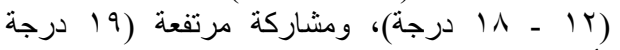

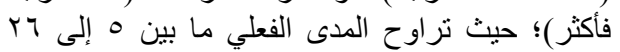
درجة.

\section{ب. المتغيرات التابعة}

مستوى معرفة المبحوثين بالتوصيات الإرشادية لإنتاج

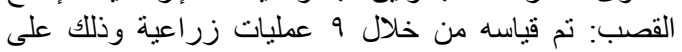

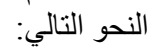

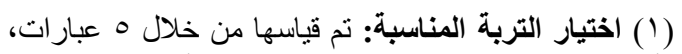

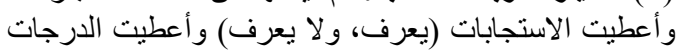

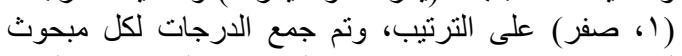

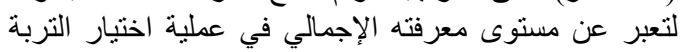

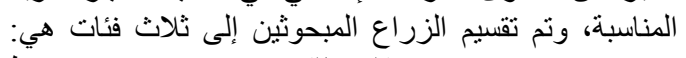

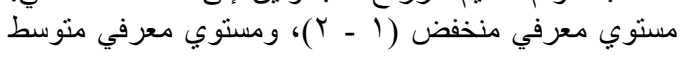

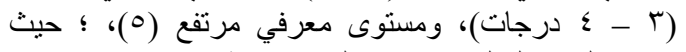

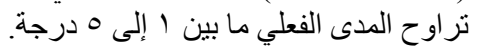

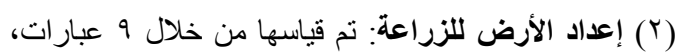

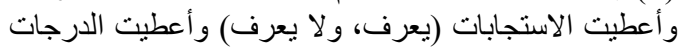

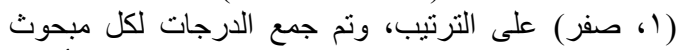

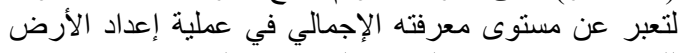

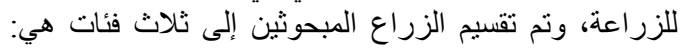

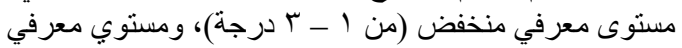

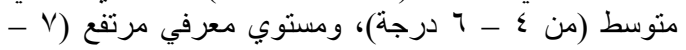

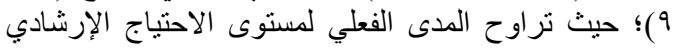
المعرفي ما بين أبراج إلى 9 درجة. 


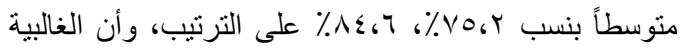

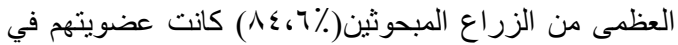

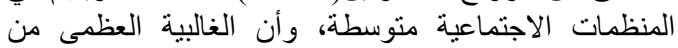

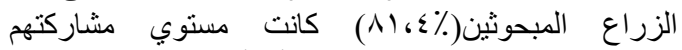

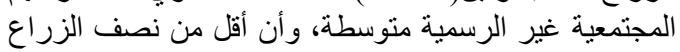

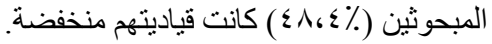

\section{ثانيا: مستوى معرفة الزراع المبحوثين بالتوصيات الإرشادية}

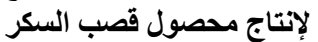

\section{ا ـ معرفة الزراع المبحوثين بعملية اختيار التربة المناسبة}

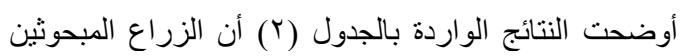

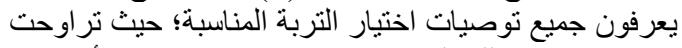

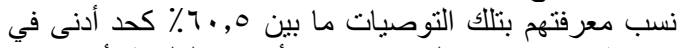

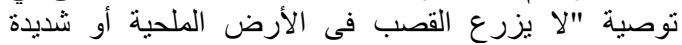

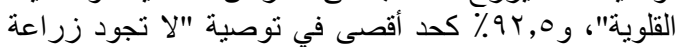

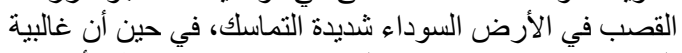

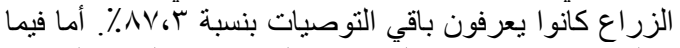

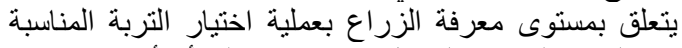

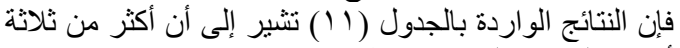

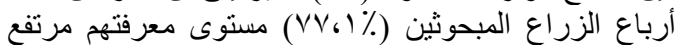

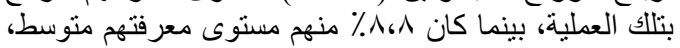

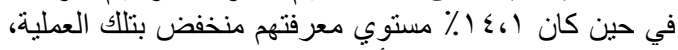

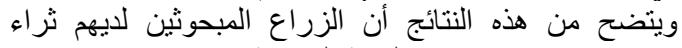
معرفي بتوصيات اختيار التربة المناسبة.

r. معرفة الزراع المبحوثين بتوصيات إعداد الأرض للزراعة

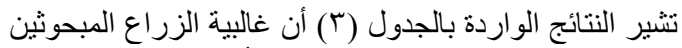

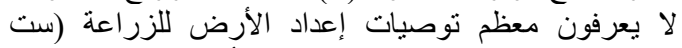

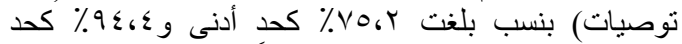

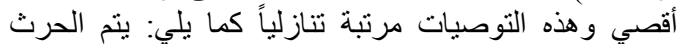

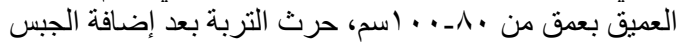

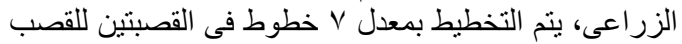

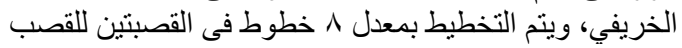

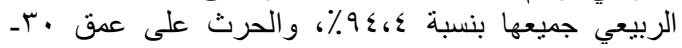

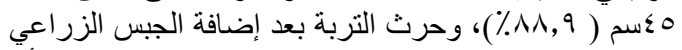

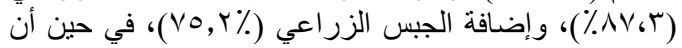

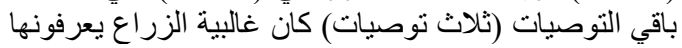

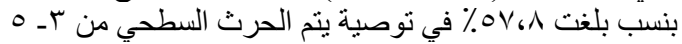

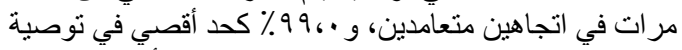

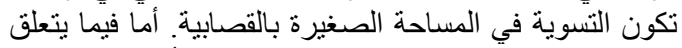

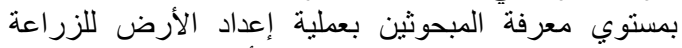

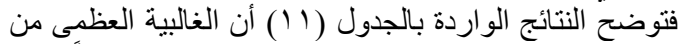

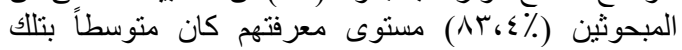

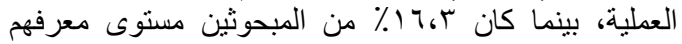

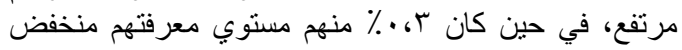

عن مستوى معرفته الإجمالي في عملية التسميد، وتم تقسيم

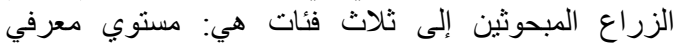

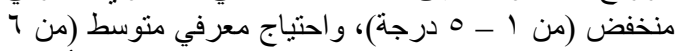

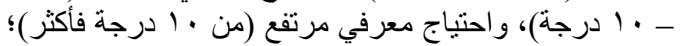

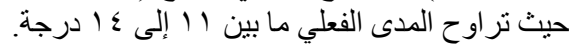

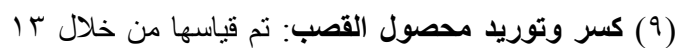

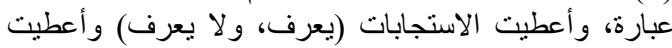

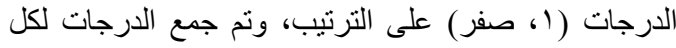

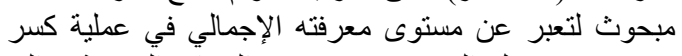

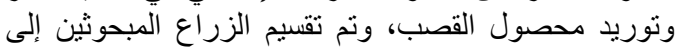

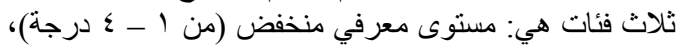

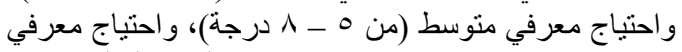

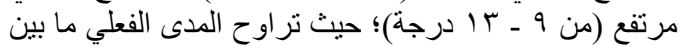
ا إلى سا درنة

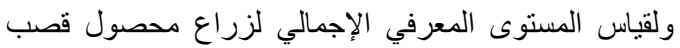

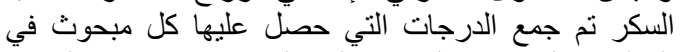

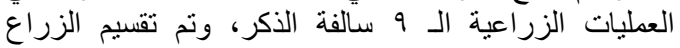

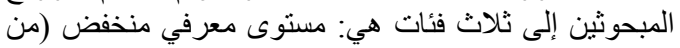

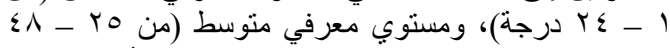

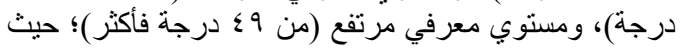

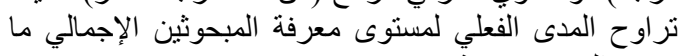
بين ا إلى الى لورجة.

\section{أدوات التحليل الاحصائي}

بعد الانتهاء من جمع البيانات وتفريغها تم تحليلها باستخدام

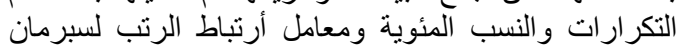

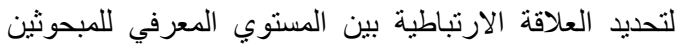

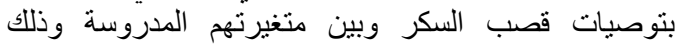
باستخدام مجمو عة البرامج الاحصيائية وئنير

\section{النتائج ومناقشتها}

\section{أولا: وصف عينة البحث}

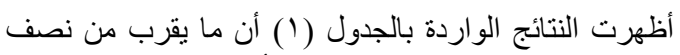

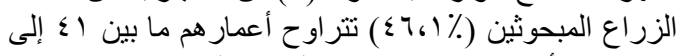

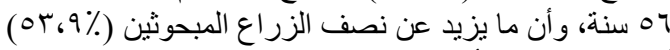

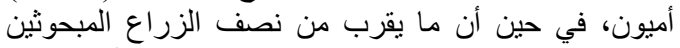

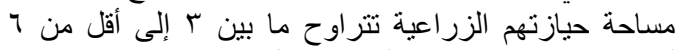

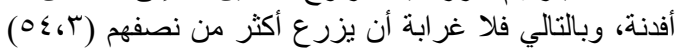

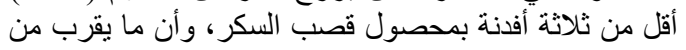

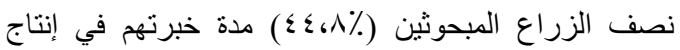

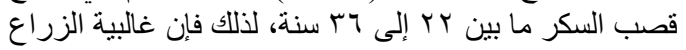

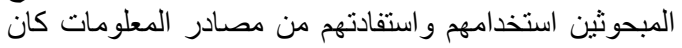


بتلاك العطلية، ويتضح من هذه النتائج أن الزراع المبحوثين لا ل يحتم على العاملين في الإرشاد الزراعي تكثيف جهودهم التنمية

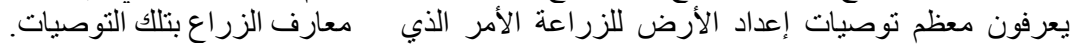

جدول ( (): التوزيع العددي و النسبي للزر اع المبحوثين وفقاً لخصائصهم الثخصبة الددروسة (ن= \ • ؟).

\begin{tabular}{|c|c|c|c|c|c|c|c|}
\hline$\%$ & عدد & الخصائص الثخصبة & 5 & $\%$ & عدد & الخصائص الثخصية & 5 \\
\hline & & استخدام مصادر المعلومات & \multirow{4}{*}{7} & \multicolumn{3}{|r|}{ 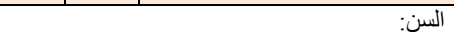 } & \\
\hline 17,7 & 01 & منخفض (0ـ 9 درجات) & & TV، & or & من 0Y - •؛ سنة & \\
\hline $\begin{array}{r}O, Y \\
\end{array}$ & Tr. & متوسط (· (1 ـ ا درجة) & & $\sum 7,1$ & $1 \leqslant 1$ & من إ - 07 سنة & \\
\hline$\Lambda_{6} r$ & ro & مرتفع (10 ـ 9 (1 درجة) & & r4,7 & 114 & من Vo vنة فأكثر & \\
\hline & & الاستفادة من مصادر المعلو & \multirow{4}{*}{$\mathrm{v}$} & & & المستوى التعليمي: & \multirow{6}{*}{ r } \\
\hline$V_{6} r$ & YY & منخفضة (r ـ ^ درجات) & & or, 9 & 170 & أمي & \\
\hline$\Lambda \varepsilon_{67}$ & roq & متوسطة (9 - ـ ا درجة) & & Yo,0 & $V \wedge$ & يقر أويكتب & \\
\hline$\Lambda_{6} r$ & ro & مرتفعة (0 ( درجة فأكثر) & & 106. & $\sum 7$ & متوسط & \\
\hline & & العضوية في المنظمات الاج & \multirow{4}{*}{$\wedge$} & $r .7$ & 11 & فوق منوسط & \\
\hline $1 \%, 1$ & $\varepsilon$ & منخفضة (درجة واحدة) & & $Y_{6} \cdot$ & 7 & جامعي & \\
\hline$\Lambda \varepsilon, 7$ & roq & متوسطة (درجتين) & & & & مساحة الحبازة الزر اعية: & \multirow{4}{*}{$r$} \\
\hline T.r & v & مرتفعة (r - ع درجات) & & rra. & 1.1 & من فدان - أقل من ؟ فدان & \\
\hline & & المشاركة المجتمعية غير الر & \multirow{4}{*}{9} & $\varepsilon 0,1$ & $1 \leqslant$. & من ؟ - أقل من 7 فدان & \\
\hline 9,1 & $r \wedge$ & منخفضة (0ـ 1) درجة) & & YI, & 70 & من 7 فدان فأكثر & \\
\hline N1، & $r \leq 9$ & متوسطة (r ( ا 1 ( درجة) & & & & المساحة المنزر عة بقصب & \multirow{4}{*}{$\varepsilon$} \\
\hline 9.0 & rq & مرتفعة (9 ( درجة فأكثر) & & $0 \leqslant, \pi$ & 177 & من فدان - أقل من ؟ فدان & \\
\hline & & القبادية & \multirow{4}{*}{1 . } & $r \varepsilon, 7$ & 1.7 & من ؟ - أقل من 7 فدان & \\
\hline$\sum \Lambda_{6} \varepsilon$ & $1 \leqslant \lambda$ & منخفضة (r - V درجات) & & 11,1 & $r \leqslant$ & من بَ فدان فأكثر & \\
\hline r4.r & 111 & متوسطة (^- با درجة) & & \multicolumn{3}{|c|}{ عدد سنوات الخبرة في إنتاج قصب السكر: } & \multirow{4}{*}{0} \\
\hline 10,5 & $\varepsilon \vee$ & مرتفعة (ع ( درجة فأكثر) & & $r V_{6} T$ & 110 & من V - & \\
\hline & & & & $\varepsilon \varepsilon, \wedge$ & $1 \% \mathrm{~V}$ & من YY - צr سنة & \\
\hline & & & & 1867 & $0 \leqslant$ & من V سنة فأكثر & \\
\hline
\end{tabular}

المصدر: استمارات الاستبيان.

جدول (ץ): التوزيع العددي و النسبي للمبحوثين وفقاً لمعرفتهم بتوصيات اختيار التربة المناسبة (ن=؟ • ؟).

\begin{tabular}{|c|c|c|c|c|c|}
\hline \multicolumn{2}{|c|}{ بعرف } & \multicolumn{2}{|c|}{ ل لا يعرف } & \multirow{2}{*}{ التوصيات } & \multirow[b]{2}{*}{ c } \\
\hline$\%$ & عدد & $\%$ & عدد & & \\
\hline AV,T & YTV & IY.V & rq & يجود القصب فى الأرض الصفر اء الجيدة الصرف & 1 \\
\hline AVGr & rTV & IY.V & rq & يجود القصب في الأرض الصفر اء الثقبلة الخالية من الأملاح & r \\
\hline$\Delta V_{6} T^{\prime}$ & TTV & IY.V & rq & لا بزرع القصب في الأرض الرملية & $\bar{r}$ \\
\hline 7.60 & 110 & $r 9,0$ & $|Y|$ & لا تجود زر اعة القصب فى الأرض السوداء شديدة التماسك & $\varepsilon$ \\
\hline 94.0 & t八T & $V_{6} 0$ & rr & لا يزرع القصب فى الأرض الملحية أو شديدة القلوية & 0 \\
\hline
\end{tabular}

المصدر: استمار ات الاستبيان.

جدول (r): التوزيع العددي و النسبي للمبحوثين وفقاً لمعرفتهم بتوصيات بإعداد الأرض للزر اعة (ن=؟ • ؟).

\begin{tabular}{|c|c|c|c|c|c|}
\hline \multicolumn{2}{|c|}{ تيعرف } & \multicolumn{2}{|c|}{ ل الا يعرف } & \multirow{2}{*}{ التوصيات } & \multirow[b]{2}{*}{ م } \\
\hline$\%$ & عدد & $\%$ & عدد & & \\
\hline $0 V_{6} \Lambda$ & IVV & $\sum Y_{6} Y_{1}$ & 149 & يتم الحرث السطحي من ــمر ات فى اتجاهين متعامدين & 1 \\
\hline 11,11 & $r \varepsilon$ & 11.9 & TVY & الحرث على عمق · r إِ سم & r \\
\hline 0.7 & IV & $9 \varepsilon$ व & r८9 & يتم الحرث العميق بعمق من • •^-.. اسم & r \\
\hline 996. & $r \cdot r$ & 16. & $r$ & تكون التسوية في المساحة الصغيرة بالقصابية & $\varepsilon$ \\
\hline $9 V_{6} \mathrm{~V}$ & r99 & T.r & $\mathrm{V}$ & التسوية في المساحاتات الكبيرة بالليزر & 0 \\
\hline$r \varepsilon ، \lambda$ & $V 7$ & VO, $Y$ & rT. & إضنافة الجبس الزر اعى & 7 \\
\hline IY.V & rq & $\lambda V_{6} T^{\prime}$ & YTV & حرث التربة بعد إضافة الجبس الزر اعى & V \\
\hline 0,9 & 11 & $\left.9 \varepsilon_{6}\right)$ & YAN & ينت التخطبط بمعدل V خطوط فى القصبتين للقصب الخريفي & $\Lambda$ \\
\hline 0,7 & IV & $9 \leqslant 6 \leqslant$ & r^9 & يتم التخطبط بمعدل ^ خطوط فى القصبتين للقصب الربيعي & 9 \\
\hline
\end{tabular}

المصدر: استمار ات الاستبيان. 


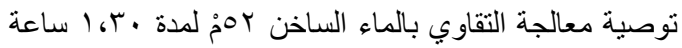

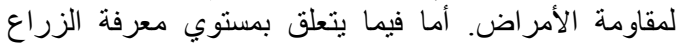

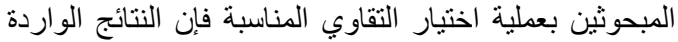

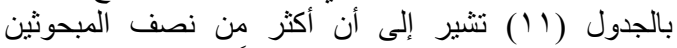

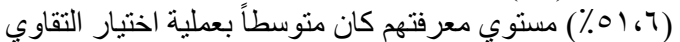

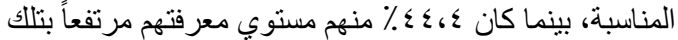

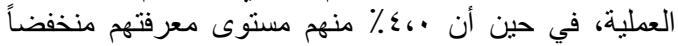

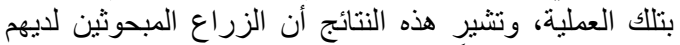

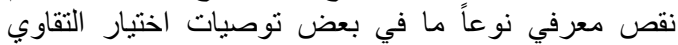

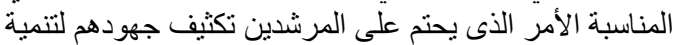
معارف الزراع بتلك التوصيات.
الم. معرفة الزراع المبحوثين بتوصيات اختيار التقاوي

المناسبة

أوضحت النتائج الواردة بالجدول (ع ) أن المبحوثين بعرفون

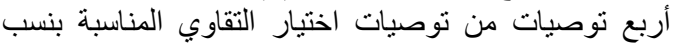

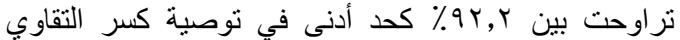

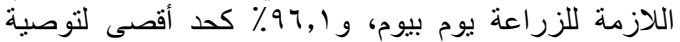

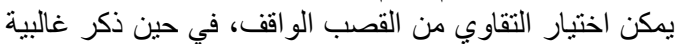

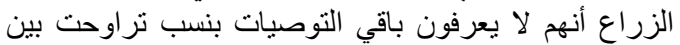

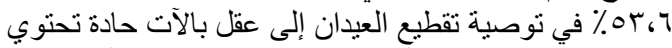

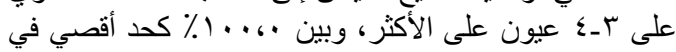

جدول (ع): التوزيع العددي و النسبي للمبحوثين وفقاً لمعرفتهم بتوصيات اختيار التقاوي المناسبة (ن=؟ • ؟).

\begin{tabular}{|c|c|c|c|c|c|}
\hline \multicolumn{2}{|c|}{ يعرف } & \multicolumn{2}{|c|}{ 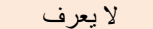 } & \multirow{2}{*}{ التوصيات } & \multirow{2}{*}{ s } \\
\hline$\%$ & عدد & $\%$ & عدد & & \\
\hline$V_{6} Y$ & rr & $9 Y_{6} \mathrm{~A}$ & 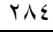 & كمية التقاوي للفدان 0,؛ طن فى حالة الزر اعة بصف ونصف & 1 \\
\hline 94.0 & TAT & 7.0 & T. & كمية التقاوي للفذان 7 طن فى حالة الزر اعة بصفين & r \\
\hline $9 \leqslant 61$ & $r \wedge \Lambda$ & 0,9 & 11 & اختيار التقاوي من محصول الغرس أو الخلفة & $r$ \\
\hline 97,1 & rqะ & $r, 9$ & ir & يمكن اختيار التقاوي من القصب الو اقف & $\varepsilon$ \\
\hline QY,Y & TAY & $\bar{V} V_{6} \Lambda$ & $r \varepsilon$ & كسر التقاوي اللازمة للزر اعة يوم بيوم. & 0 \\
\hline$\sum 7_{6} \varepsilon$ & $1 \leqslant Y$ & Or.7 & $17 \varepsilon$ & تقطيع العيدان إلى عقل بآلات حادة تحتوي على بـــ عيون على الأكثر & 7 \\
\hline$\cdot$ & $\cdot$ & $1 \cdots \cdot \cdot$ & $r \cdot 7$ & 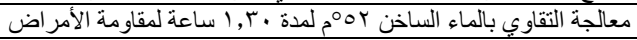 & $\begin{array}{l} \\
\end{array}$ \\
\hline
\end{tabular}

المصدر: استمار اتجة الاستبيان.

المبحوثين بتوصيات مبعاد وطريقة الزراعة فإن النتائج

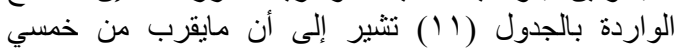

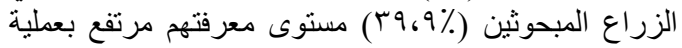

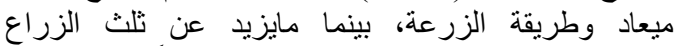

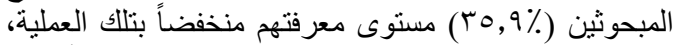

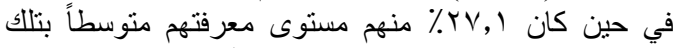

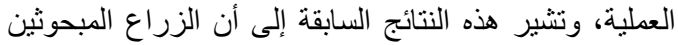

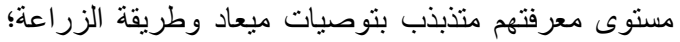

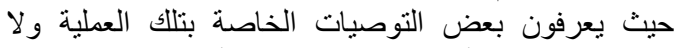

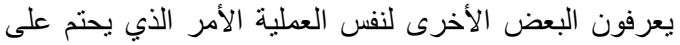
الجهاز الإرشادي تكثيف جهوده لتوعية الزراع بالتوصية الإنيات

التي لا بعرفونها.
"َ. معرفة الزراع المبحوثين بتوصيات ميعاد وطريقة الزراعة

بينت النتائج الواردة بالجدول (0) أن الزراع المبحوثين لا لأل

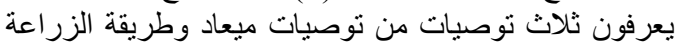

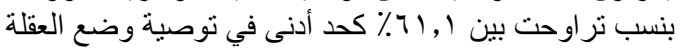

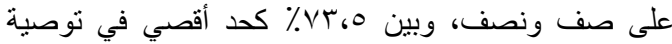

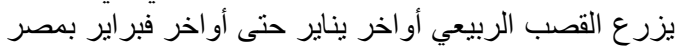

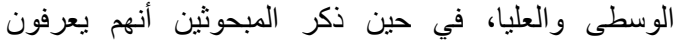
التوصيتين المتبقيتين من التوصيات الإرشادية الخاصة بميعاد

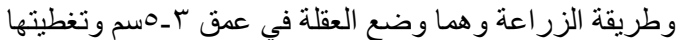

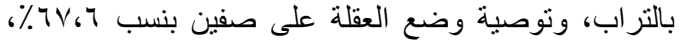

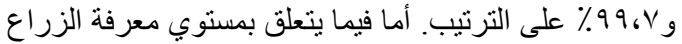

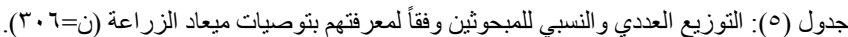

\begin{tabular}{|c|c|c|c|c|c|}
\hline \multicolumn{2}{|c|}{ ميعرف } & \multicolumn{2}{|c|}{ ل الا يعرف } & \multirow{2}{*}{ 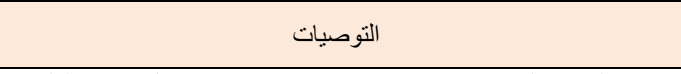 } & \multirow[b]{2}{*}{ s } \\
\hline$\%$ & عدد & $\%$ & عدد & & \\
\hline rA, r & $11 \mathrm{~V}$ & 71,1 & 119 & يزرع القصب الخريفي في شهرب سبتمبر و اكتوبر بمصر الوسطى و العليا & 1 \\
\hline Y T.0 & Al & $\mathrm{VTr}, \mathrm{O}$ & Tro & يزر ع القصب الربيعي أواخر يناير حتى أواخر فبر اير بمصر الوسطى و العليا & r \\
\hline $7 V .7$ & T.V & rras & 99 & وضع العقلة في عمق r-0سم وتغطيتها بالتزراب & $r$ \\
\hline rA, 6 & 119 & 71,1 & IAV & وضع العقلة على صف ونصف & $\varepsilon$ \\
\hline $996 \mathrm{~V}$ & $r .0$ & .6 & 1 & وضع العقلة على صفين & $\circ$ \\
\hline
\end{tabular}

المصدر: استمارات الاستبيان. 
وتنشير هذه النتائج السابقة أن الزراع المبحوثين لايهم احتياج

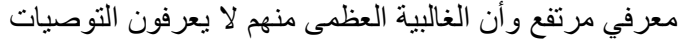
الخاصة بالترقيع.

\section{\. معرفة الزراع المبحوثين بتوصيات الترقيع}

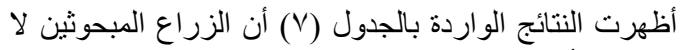

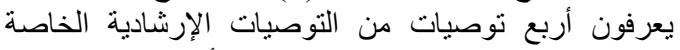

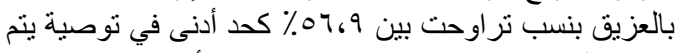

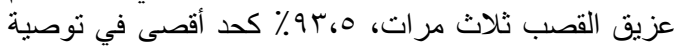

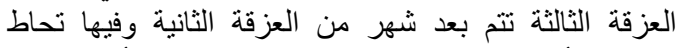

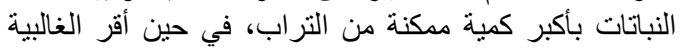

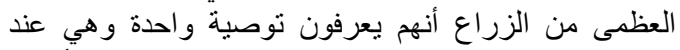

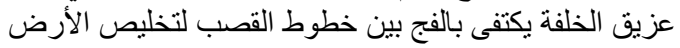

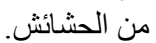

\section{•ـ معرفة الزراع المبحوثين بتوصيات الترقيع}

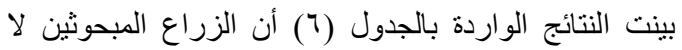

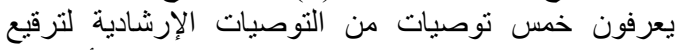

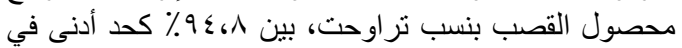

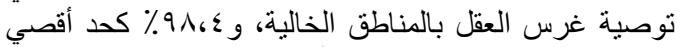

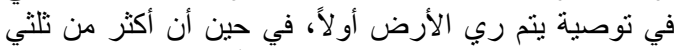

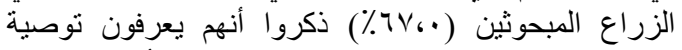

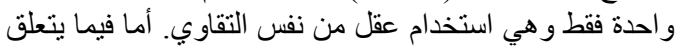

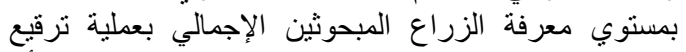

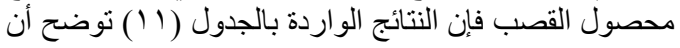

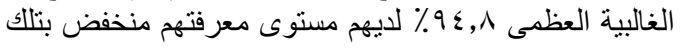

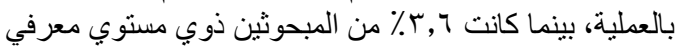

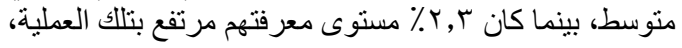

جدول (ך): التوزيع العددي و النسبي للمبحوثين وفقاً لمعرفتهم بتوصيات الترقيع (ن=7 • (T).

\begin{tabular}{|c|c|c|c|c|c|}
\hline \multicolumn{2}{|c|}{ يعرف } & \multicolumn{2}{|c|}{ ل لا يعرف } & \multirow{2}{*}{ التوصيات } & \multirow[b]{2}{*}{5} \\
\hline$\%$ & عدد & $\%$ & عدد & & \\
\hline $7 V_{6}$. & r.O & بr. & 1.1 & استخدام عقل من نفس الثقاوي & 1 \\
\hline$r_{6} \cdot$ & 7 & $9 \Lambda_{6}$. & $r \ldots$ & غمر المناطق الخالية من النباتات بالماء & T \\
\hline $0, Y$ & 17 & $9 \leq 6 \wedge$ & rq. & غرس العقل بالمناطق الخالية & $r$ \\
\hline 1,7 & 0 & $9 \wedge ، \varepsilon$ & $r \cdot 1$ & ينت ري إلارض أولاً & $\varepsilon$ \\
\hline$r_{6} \cdot$ & 7 & $9 \Lambda_{6}$. & $r \ldots$ & اقتتلاع بعض النباتات بجذور ها من المناطق المزدحمة & 0 \\
\hline T.r & $\begin{array}{l} \\
\end{array}$ & $9 V_{6} \mathrm{~V}$ & rq9 & إعادة غرس النباتات المقلو عة فى المناطق الخالية & 7 \\
\hline
\end{tabular}

المصدر: استمارات الاستبيان.

جدول (V): التوزيع العددي و النسبي للمبحوثين وفقاً لمعرفتهم بتوصيات عزيق القصب (ن=؟ • ؟).

\begin{tabular}{|c|c|c|c|c|c|}
\hline \multicolumn{2}{|c|}{ يعرف } & \multicolumn{2}{|c|}{ لا يعرف } & \multirow{2}{*}{ التوصيات } & \multirow[b]{2}{*}{5} \\
\hline$\%$ & 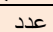 & $\%$ & عدد & & \\
\hline$\varepsilon r_{6}$ & $T \pi$ & 07.9 & $T V \varepsilon$ & يتم عزيق القصب ثلاث مر ات & 1 \\
\hline $1 \varepsilon_{6} \mathrm{~V}$ & «o & $10, \mathrm{r}$ & YTI & العزقة الأولى تجرى بعد شهر الى شهر ونصف من. الزر اعة & r \\
\hline$V_{6} 0$ & rT & 94.0 & TAT & العزقة الثانية تتم بعد شهر من العزقة الأولى & $r$ \\
\hline 7,0 & r. & 94.0 & rAT & الثالثة بعد شهر من الثانية وفيها تحاط النباتات بكمبة ممكنة من التراب & $\varepsilon$ \\
\hline $97 . \mathrm{V}$ & r97 & $r_{6} r^{2}$ & 1. & يكتفى في عزيق الخلفة بالفج بين الخطوط لتخليص الأرض من الحشائش & 0 \\
\hline
\end{tabular}

المصدر : استمارات الاستبيان.

محصول القصب بنسب تراوحت بين 0، ؛ \% كحد أدنى في

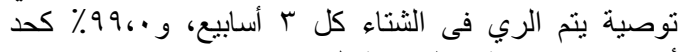

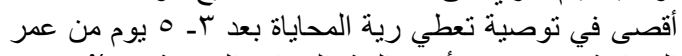

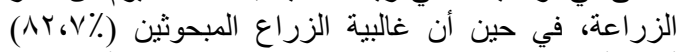

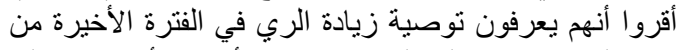

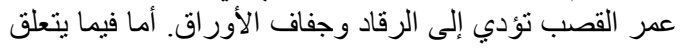

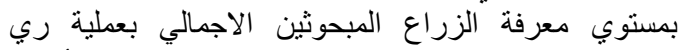

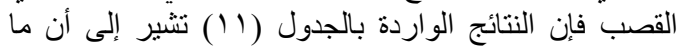

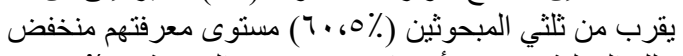

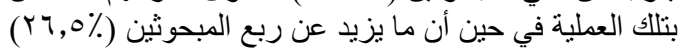

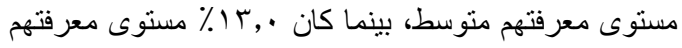

أما فيما يتعلق بمستوي معرفة الزراع المبحوثين الإجمالي

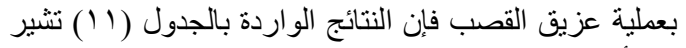

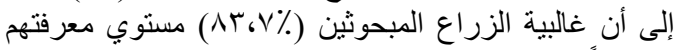

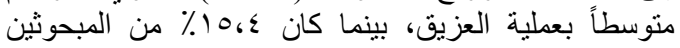

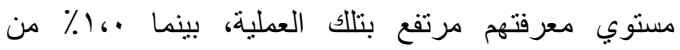
المبحوثين مستوى معرفتهم منخفض مرنغ بتلك العملية.

V. معرفة الزراع المبحوثين بتوصيات ري محصول القصب

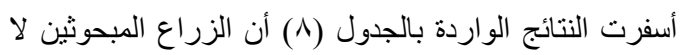

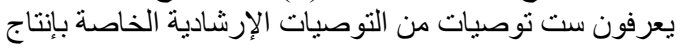


ضرورة قيام المرشدين الزراعيين بتكثيف الجهود اللازمة لرفع مستوى معرفة الزراع بتلك التورين التوصيات.

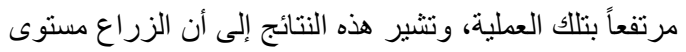

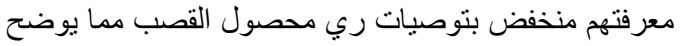

جدول (^): التوزيع العددي و النسبي للمبحوثين وفقاً لمعر فتهم بتوصيات ري محصول القصب (ن=؟ • ؟).

\begin{tabular}{|c|c|c|c|c|c|}
\hline \multicolumn{2}{|c|}{ 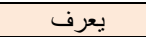 } & \multicolumn{2}{|c|}{ ل الا يعرف } & \multirow{2}{*}{ التوصيات } & \multirow[b]{2}{*}{ 5 } \\
\hline$\%$ & عدد & $\%$ & عدد & & \\
\hline 1964 & 09 & $\Lambda \cdot 6 \mathrm{~V}$ & $r \leqslant V$ & يؤدى نقص الماء الى قصر السلاميات ونقص كمية العصبير وزيادة نسبة الألياف & 1 \\
\hline YT.0 & 入I & $V Y, 0$ & rro & يؤدى الإسر اف في الري الى تعفن العقل وموت البر اعم ونقص المحصول & $T^{r}$ \\
\hline AY, & ror & $1 V_{6} \mathrm{~T}$ & or & زيادة الري فى الفترة الأخيرة من عمر القصب تؤدى الى الرقاد وجفاف الأوراق & $r$ \\
\hline 1,6 & $r$ & 996. & $r \cdot r$ & تعطى رية المحاياة بعد بــ يوم من الزر اعة & $\varepsilon$ \\
\hline$\varepsilon r, 0$ & 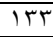 & 07,0 & $1 \mathrm{inT}$ & ينم الري فى الثتاء كل ب أسابيع & 0 \\
\hline Tr، & 99 & $7 V_{6} 7$ & $Y \cdot V$ & يكون الري فى الربيع والخريف كل أسبو عين & 7 \\
\hline MY.V & $1 \ldots$ & $7 V_{6} T$ & $Y \cdot T$ & يتم رب النباتات في الصيف كل V-. - أيام & $\mathrm{V}$ \\
\hline
\end{tabular}

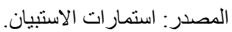

الفج (بنسبة 7،97\%)، وتوصية اضافة . .بكجم سوبر

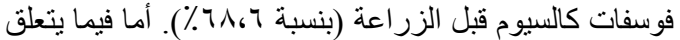

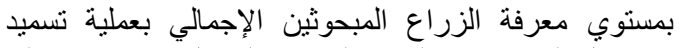

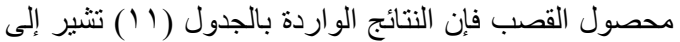

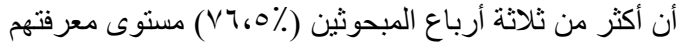

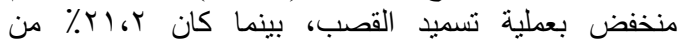

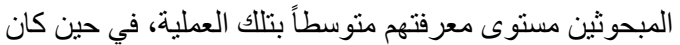

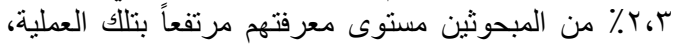

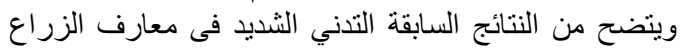

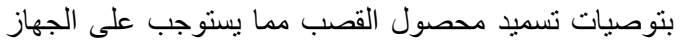

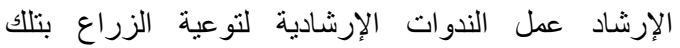
التوصيات. - الات

\section{^. معرفة الزراع المبحوثين بتوصيات تسميا محصول القصب}

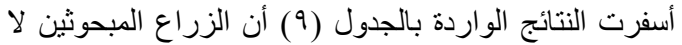

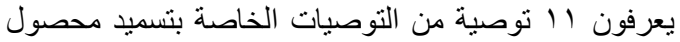

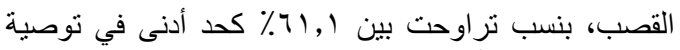

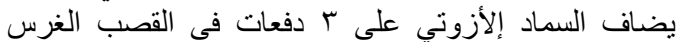

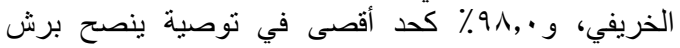

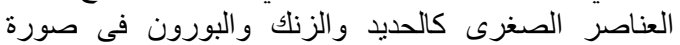

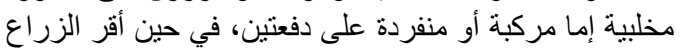

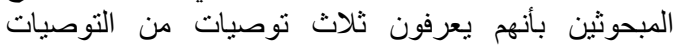

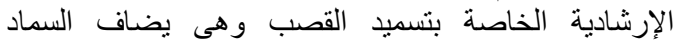
الأزوتي على دفعتين فى القصب الخلفة الفية، الدفعة الأولى بعد الفي

جدول (9): التوزيع العددي و النسبي للمبحوثين وفقاً لمعرفتهم بتوصيات تسميد محصول القصب (ن=7 • ץ).

\begin{tabular}{|c|c|c|c|c|c|}
\hline \multicolumn{2}{|c|}{ 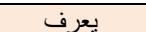 } & \multicolumn{2}{|c|}{ 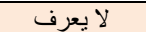 } & \multirow{2}{*}{ التوصيات } & \multirow[b]{2}{*}{ 5 } \\
\hline$\%$ & عدد & $\%$ & عدد & & \\
\hline$r .9$ & Ir & 97,1 & rq & 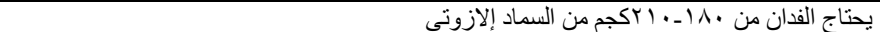 & 1 \\
\hline$r \Lambda_{6} 9$ & 119 & 7161 & IAV & يضاف السماد إلازوتي على ب دفعات فى القصب الغرس الخريفي & r \\
\hline $1 V_{6} 7$ & $0 \leqslant$ & AY، & YOY & الدفعة الأولى ثلث الكمية وتضاف بعد العزقة الثانية & $r$ \\
\hline$\Lambda_{6} \wedge$ & TV & 91,4 & rVq & الدفعة الثانية ثلث الكمية وتضاف بعد العزقة الثالثة & $\varepsilon$ \\
\hline$V_{60}$ & rt & $9 Y_{6} 0$ & tAr & الدفعة الثالثة الثلث المتبقي وتضاف بعد الدفعة الثانية بشهر & 0 \\
\hline$r .7$ & 11 & $976 \varepsilon$ & r90 & يضاف السماد إلازوتي على دفعتين فى القصب الغرس الربيعي & 7 \\
\hline r.7 & $\Lambda$ & $9 \vee ، \varepsilon$ & rqA & الدفعة الأولى نصف الكمية وتضاف بعد العزقة الثانية & $\mathrm{V}$ \\
\hline T.7 & $\Lambda$ & $9 V_{6} \varepsilon$ & rqA & الدفعة الثانية النصف الآخر وتضاف بعد العزقة الثالثة & $\Lambda$ \\
\hline 7967 & YIT & $r \cdot ، \varepsilon$ & 94 & يضاف السماد إلازوتي على دفعتين فى القصب الخلفة & 9 \\
\hline 79.7 & YIT & $r \cdot ، \varepsilon$ & 94 & الدفعة الأولى بعد الفج & $1 \cdot$ \\
\hline 11167 & ov & N!، & $r \leqslant 9$ & الدفعة الثانية بعدها بشهر & 11 \\
\hline $7 \wedge, 7$ & Y.. & rl, & 97 & اضافة . . اكجم سوبر فوسفات كالسيو قبل الزر اعة & ir \\
\hline$r \Lambda_{6} \Lambda$ & $\wedge \wedge$ & $V /, Y$ & YIA & اضافة من •0 ـ . . اكجم سوبر سلفات بوتاسيوم & 14 \\
\hline$r_{6} \cdot$ & 7 & $9 \Lambda_{6} \cdot$ & $r \cdots$ & رش العناصر الصغرى كالحديد و الزنكك و البورون فى صورة مخلبية إما مركبة أو منفردة على دفعتين & $1 \leq$ \\
\hline
\end{tabular}

المصدر: استمار ات الاستبيان. 


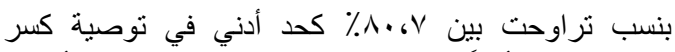

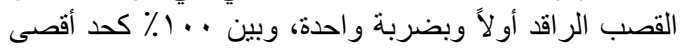

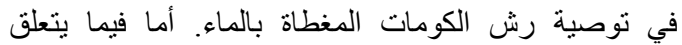

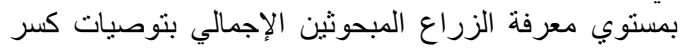

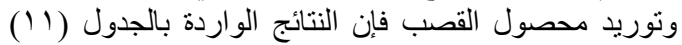

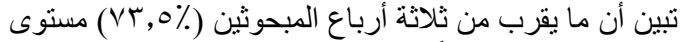

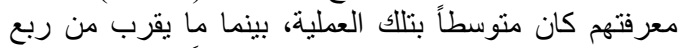

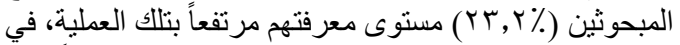

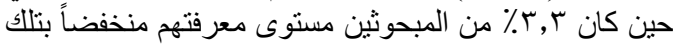

العملية.
9. معرفة الزراع المبحوثين بتوصيات كسر وتوريد محصول القصب (الهر

أوضحت النتائج الواردة بالجدول (• (1) أن الزراع المُون المبحوثين

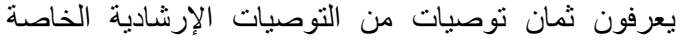

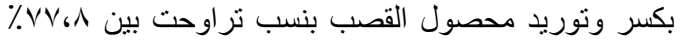

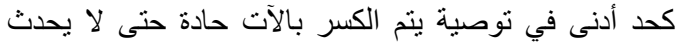

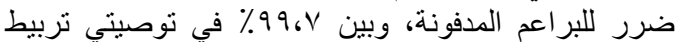

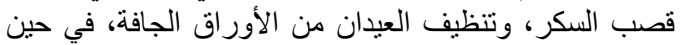

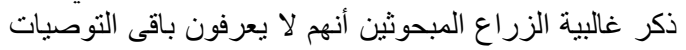

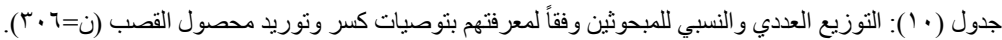

\begin{tabular}{|c|c|c|c|c|c|}
\hline \multicolumn{2}{|c|}{ يعرف يعا } & \multicolumn{2}{|c|}{ 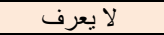 } & \multirow{2}{*}{ التوصيات } & \multirow[b]{2}{*}{ s } \\
\hline$\%$ & عدد & $\%$ & عدد & & \\
\hline $99 . \mathrm{V}$ & $r .0$ & $.6 \mathrm{~T}$ & 1 & تربيط قصب السكر & 1 \\
\hline$A V_{6} T^{2}$ & rTY & $1 \mathrm{~T}_{6} \mathrm{~V}$ & r9 & عدم ري القصب قبل الكسر ب بـ ـ أسابيع حتى لا ينخفض المحتوى السكرى & $r$ \\
\hline $9 \wedge, \varepsilon$ & $r .1$ & 1.7 & o & كسر محصول القصب عند إتمام نضج المحصول & $r$ \\
\hline$V V_{6} \Lambda$ & rTA & YYGr & 71 & يتم الكسر بآلات حادة حتى لا يحدث ضرر للبر اعم المدفونة & $\varepsilon$ \\
\hline 7.9 & YI & 94.1 & r/o & تغطية الكومات بأوراق القصب الجافة بسمك OY سم & 0 \\
\hline. $\mathrm{r}$ & 1 & $99 . \mathrm{V}$ & $r .0$ & جمع البو ال ونقله في عربات خاصة للمصنع & 7 \\
\hline 19.4 & 09 & A.rV & $r \leq V$ & كسر القصب الر اقد أولأوبضربة واحدة & $\mathrm{V}$ \\
\hline Nr.V & ror & IV.T & or & كسر الكمية التي يمكن شحنها فى نفس اليوم & $\Lambda$ \\
\hline 90,1 & rq1 & $\varepsilon .9$ & 10 & التقثير الجيد للعيدان واز الة القالوح و الطين العالق بالعيدان لعدم زيادة الاستقطاع & 9 \\
\hline $996 \mathrm{~V}$ & $r .0$ & .64 & 1 & تنظيف العيدان من الأوراق الجافة & 1. \\
\hline 94,0 & TAT & 7.0 & $r \cdot$ & تنظيف العيدان من بقايا الجذور & 11 \\
\hline $10 ، \varepsilon$ & $\varepsilon V$ & $\wedge \varepsilon ، 7$ & roq & يجب إلا تزيد عمليتي الكسر و التوريد عن حساعة & IT \\
\hline · & $\cdot$ & $1 \cdots$ & $r \cdot T$ & رش الكومات المغطاة بالماء & 14 \\
\hline
\end{tabular}

المصدر : استمارات الاستبيان.

جدول (1 (1): التوزيع العددي و النسبي للمبحوثين وفقاً لمستوى معرفة المبحوثين بعمليات انتاج محصول القصب (ن=7 • r).

\begin{tabular}{|c|c|c|c|c|c|c|}
\hline \multicolumn{2}{|c|}{ مستوى مرتفع } & \multicolumn{2}{|c|}{ مستوى متو سط } & \multicolumn{2}{|c|}{ مستوى منخفض } & \multirow{2}{*}{ العمليات الزراعية في القصب } \\
\hline$\%$ & عدد & $\%$ & عدد & $\%$ & عدد & \\
\hline$\left.V_{V_{6}}\right)$ & TMT & $\Lambda_{6} \Lambda_{1}$ & TV & $1 \varepsilon_{6} 1$ & $\varepsilon r$ & اختيار التربة المناسبة \\
\hline 17.4 & 0. & NT، & roo & .6 & 1 & إعداد الأرض للزر اعة \\
\hline ะะ، & 144 & 01,7 & 101 & $\varepsilon_{6}$ & IT & اختبار التقاوي المناسبة \\
\hline$r V, 1$ & NT & ro, q & 11. & rq,9 & $11 \pi$ & ميعاد وطريقة الزر اعة \\
\hline r.T & $\mathrm{V}$ & $r .7$ & 11 & $9 \leq 61$ & $r \wedge \Lambda$ & ترقيع محصول القصب \\
\hline $10, \varepsilon$ & $\varepsilon V$ & NT,V & Y07 & 16. & $r$ & عزيق محصول القصب \\
\hline $1 \pi_{6}$ & $\varepsilon \cdot$ & r7.0 & 入I & 7.60 & 110 & ري محصول القصب \\
\hline T.T & $\mathrm{V}$ & YI, Y & 70 & $V 7,0$ & TTE & تسميد محصول القصب \\
\hline Tr.t & v) & $V r_{6} 0$ & rro & r.r & 1. & كسر وتوريد محصول القصب \\
\hline
\end{tabular}

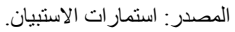

مستوى معرفتهم الاجمالية بتوصيات انتاج قصب السكر كان

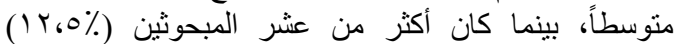

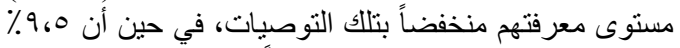

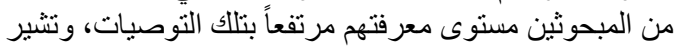

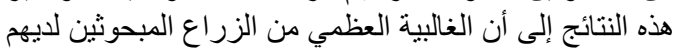

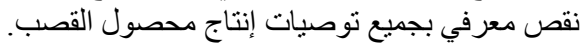

\section{أمن المستوى المعرفي الإجمالي بالتوصيات الإرشادية لإنتاج

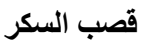

أظهرت النتائج بالجدول (r ا ( ) فيما يتعلق بالمستوي المعرفي

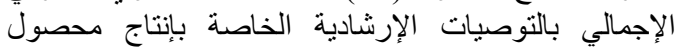
قصب السكر أن ما يزيد عن ثلاثة أرباع المبحوثين (VV،A\%) 
Basheer et al. / Archives of Agriculture Sciences Journal 4(1) 41-53, 2021.

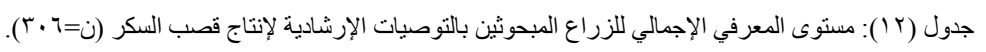

\begin{tabular}{|c|c|c|}
\hline$\%$ & عدد & المستوى المعرفي الاجمالي \\
\hline IYGV & rq & منخفض (من I - گ ז درجة) \\
\hline$V V_{6} A$ & TrA & متوسط (من 0Y - ^^ درجة) \\
\hline 9.0 & rq & مرتفع (9 ؛ درجة فأكثر) \\
\hline
\end{tabular}

المجتمعية غير الرسمية، و القيادية. وأوضحت النتائج الواردة

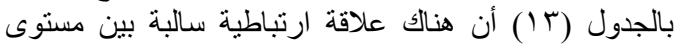

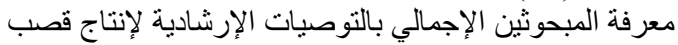

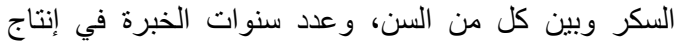

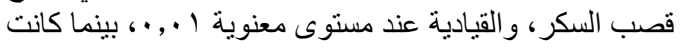

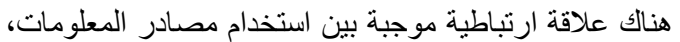

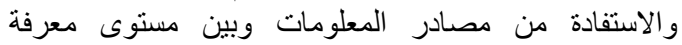

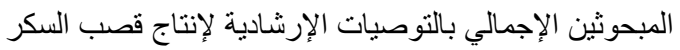

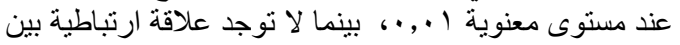

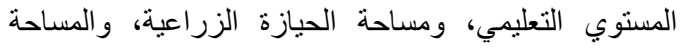

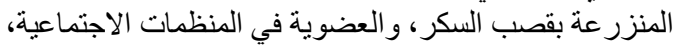

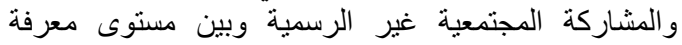

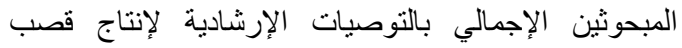
السكر.
ثالثا: العلاقات الارتباطية بين المتغيرات المستقلة المدروسة

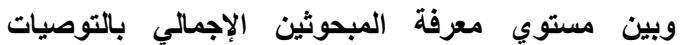
الإرشادية لإنتاج قصب السكر معرة

لتحديد العلاقة بين مستوى معرفة المبحوثين الإجمالي

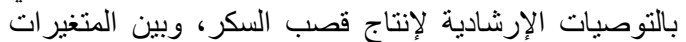
المستقلة المدروسة تم صياغة الفرض الإنة الإحصائي القائل " لانئل

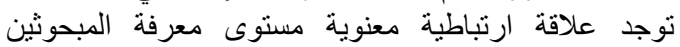

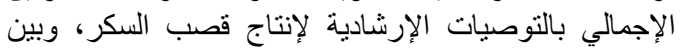

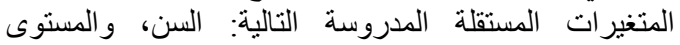

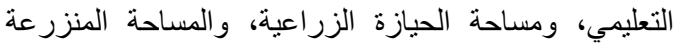

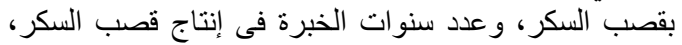

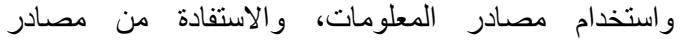
المعلومات، و العضوية في المنظمات الاجتماعية، و المشاركة

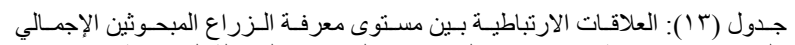

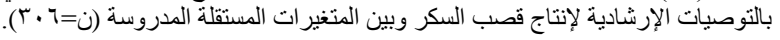

\begin{tabular}{|c|c|}
\hline معامل ارتباط سبيرمان & المتغير ات المستقلة \\
\hline **., Y.O- & 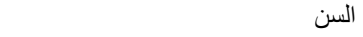 \\
\hline $.61 \ldots$ & المستوى التعليمي \\
\hline $9.79-$ & مساحة الحيازة الزراعية \\
\hline ...Y. - & المساحة المنزرعة بقصب السكر \\
\hline$* * ., 17 .-$ & عدد سنو ات الخبرة في إنتاج قصب السكر \\
\hline$* * ., 10 \leqslant$ & استخدام مصادر المعلومات \\
\hline$* * ., 100$ & إلاستفادة من مصادر المعلومات \\
\hline $.6 .1 \mathrm{~V}$ & العضوية في المنظمات الاجتماعية \\
\hline$\cdots+\cdots$ & المشاركة المجتمعية غير الرسمية \\
\hline$* * ., 197-$ & 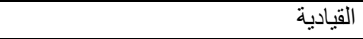 \\
\hline
\end{tabular}

علاقة ارتباطية معنوية بين مستوى معرفة الزراع المبحوثين

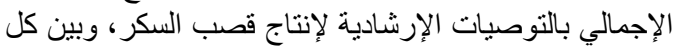

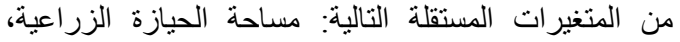

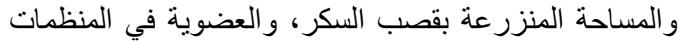

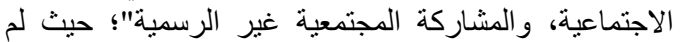

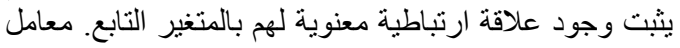

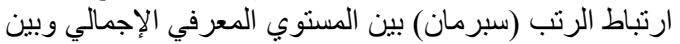
المتغير ات المستقلة المدروسة.
وبناءً على ما أظهرته النتائج سالفة الذكر يمكن رفض أجزاء

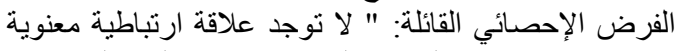

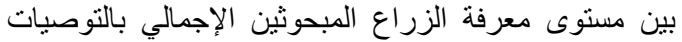

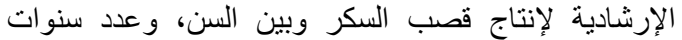

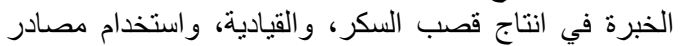

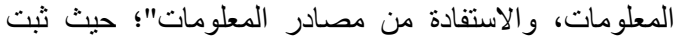

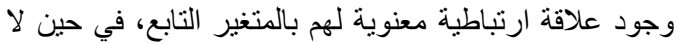

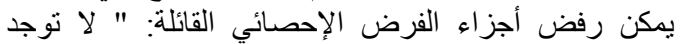




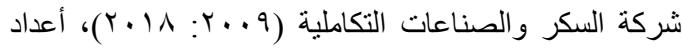

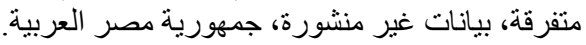

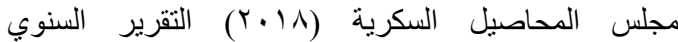

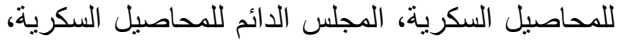
وزارة الزراعة و واستصلاح الأراضي، القيلة القاهرة، جمهورية مصر العربية.

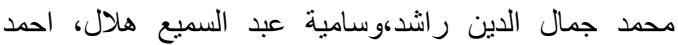

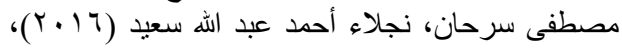

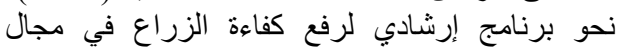

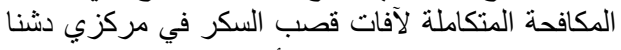

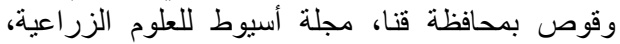

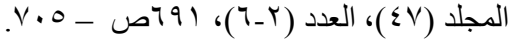

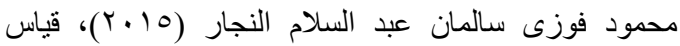
معارف الزراع لتوصيات المكافحة المتكاملة لآفات

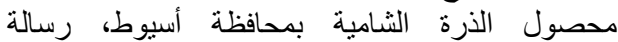
ماجستير، كلية الزر اعة، جامعة أسيوط، جمهورية مصر الفر

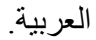

من خلال النتائج التي تم التوصل إليها يمكن الخروج بعدد من التئ التوصيات الهامة على النحو التالي:

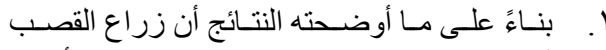

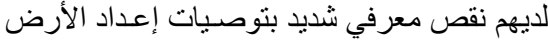

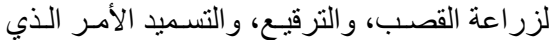

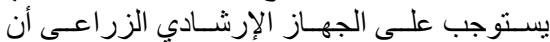

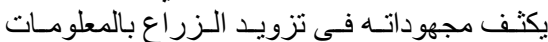

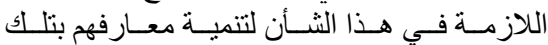

$$
\text { التوصيات. - الت }
$$

عمل حقول إرشـادية للزر اع لتزويـهم بالمعـارف

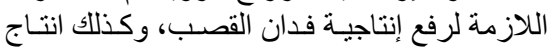

$$
\text { محصول عالي الجودة. }
$$

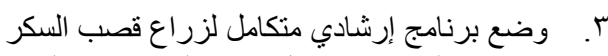

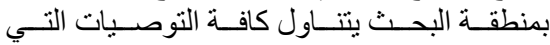

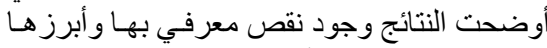

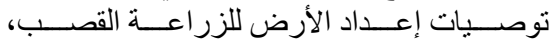
و الترقيع، و التسميد

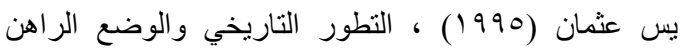

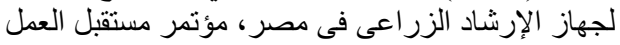

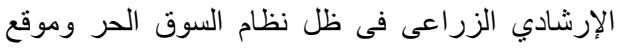

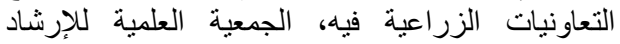

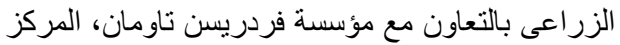

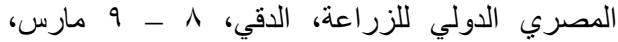
جمهورية مصر العربية.

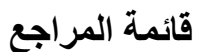

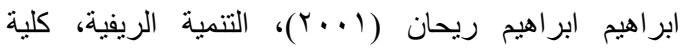
الزراعة، جامعة عين شمس، القاهرة، جمهورية مصر الهر

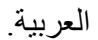

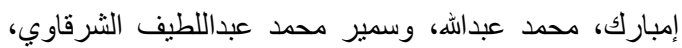
حمدي محمد عوض (Y) (Y. T) ، أسباب الفجوة الإنتاجية

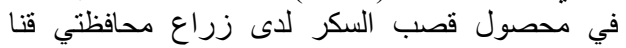

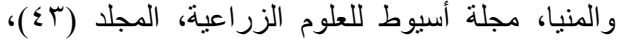

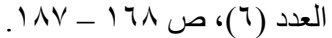

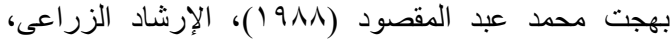

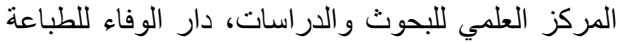
و النشر و التوزيع، المنصورة.

الجهاز المركزي للتعبئة و العامة و الإحصاء، الكتاب الإحصائي

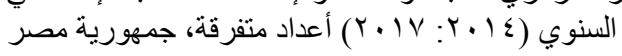

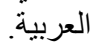

سعد احمد هجرس (1997))، موسوعة مصر الحديثة، المجلد السادس، القاهرة، جمهورية مصر العربية. 